\title{
Treating anxious expectations can improve dyspnoea in patients with COPD
}

\author{
Andreas von Leupoldt (10) \\ Affiliation: Health Psychology, University of Leuven, Leuven, Belgium. \\ Correspondence: Andreas von Leupoldt, Health Psychology, University of Leuven, Tiensestraat 102, B-3000 \\ Leuven, Belgium. E-mail: andreas.vonleupoldtappw.kuleuven.be
}

@ERSpublications

The detection and treatment of anxious expectations can improve dyspnoea in patients with COPD http://ow.ly/jnBR30efnhj

Cite this article as: von Leupoldt A. Treating anxious expectations can improve dyspnoea in patients with COPD. Eur Respir J 2017; 50: 1701352 [https://doi.org/10.1183/13993003.01352-2017].

Chronic obstructive pulmonary disease (COPD) is a worldwide leading cause of morbidity and mortality and associated with great individual, societal and economic burden [1]. Dyspnoea is the threatening cardinal symptom and related to a worse course of COPD, including drastic reductions in quality of life and even increased mortality risk [2,3]. Dyspnoea is a multi-dimensional subjective experience that encompasses not only the perception of sensory signals (dyspnoea intensity), but also important immediate and long-term affective aspects (dyspnoea unpleasantness, dyspnoea anxiety, suffering) [2-4]. In many patients, dyspnoea can be persistent, despite optimal treatment efforts, which was recently termed "chronic breathlessness syndrome" [5]. Notwithstanding, reducing dyspnoea is a major treatment goal in COPD [6] and neglecting it has previously been discussed in a thought-provoking article in this journal as a potential violation of human rights [7].

In addition to the prominent pulmonary manifestations of COPD, patients often suffer from various extrapulmonary symptoms and comorbidities, which further add to the burden of the disease [8,9]. Among these, psychological symptoms, such as anxiety and depression, are very common in COPD and related to various negative health outcomes, including greater dyspnoea [10-12]. For example, COPD patients with high anxiety levels report more dyspnoea during everyday life [13], during pulmonary rehabilitation [14], and during resistive loaded breathing tests [15] compared to patients with low anxiety levels. Alarmingly, comorbid psychological symptoms remain undiagnosed in the majority of COPD patients and, thus, untreated [11].

But how can psychological symptoms such as anxiety lead to greater dyspnoea in COPD patients? Although several potential physiological and behavioural pathways have been suggested $[11,16]$, respective knowledge remains still limited. Some authors have emphasised that after repeated aversive experiences of dyspnoea, patients develop fear and anxiety and subsequently avoid respective dyspnoea-related situations and contexts such as physical activities. This maladaptive avoidance behaviour can result in progressive deconditioning and physiological deterioration, which further increases dyspnoea at even lower activity levels and contributes to disease progression [17, 18]. Following successful models in other symptom domains, such as the fear-avoidance model of chronic pain [19], especially the anxious expectation or

Received: July 062017 | Accepted after revision: July 092017

Support statement: A. von Leupoldt is supported by a research grant from the Research Fund KU Leuven, Belgium (STRT/13/002), by an infrastructure grant from the Herculesstichting, Belgium (AKUL/13/07), and by the "Asthenes" long-term structural funding Methusalem grant (\#METH/15/011) by the Flemish Government, Belgium. Funding information for this article has been deposited with the Crossref Funder Registry.

Conflict of interest: Disclosures can be found alongside this article at erj.ersjournals.com

Copyright CERS 2017 
anticipation of dyspnoea and respective dyspnoea-related fear were more recently suggested to play an important role within this spiral of decline $[20,21]$. In fact, studies demonstrated that dyspnoea-related fear is associated with increases in dyspnoea and reductions in general psychological well-being, exercise performance and quality of life, as well as structural brain changes in COPD patients [21, 22]. A basic assumption underlying these models is that patients have learned to fear dyspnoea by forming associations between certain situations/contexts and the aversive experience of dyspnoea in these situations/contexts. Moreover, previous neuroimaging studies in healthy individuals have demonstrated that negative affective states and traits including anxiety not only influence the perception, but also the brain processing of respiratory stimuli [23]. Notably, brain responses can already be observed when dyspnoea is merely expected, i.e. in response to cues, which subjects had learned as signals for the subsequent occurrence of dyspnoea [24-28]. These anticipatory responses have been observed in brain areas that partly overlap with those during the subsequent perception of dyspnoea and were related to increased anxiety levels.

The question arises how we can treat both dyspnoea and anxiety? Currently, multidisciplinary pulmonary rehabilitation including intensive physical exercise training is the single most effective treatment for COPD with evidence-based beneficial effects in several domains. Notably, these include improvements of both dyspnoea and psychological symptoms such as anxiety $[6,29]$. It has been suggested that as well as improved physiological functioning, parts of these favourable effects are caused by exposing patients in the supervised and "safe" pulmonary rehabilitation context to feared situations such as physical activity [3032]. In this way, patients can learn new, less anxiety-laden associations between these situations/contexts and dyspnoea, and can correct anxious expectations, which ultimately results in reduced dyspnoea and reduced anxiety. However, little-to-nothing is currently known about the neural processing of dyspnoea in patients with COPD, particularly the brain processes that underlie their experience of dyspnoea and anxiety, mutual (learned) associations and anxious expectations, and their potential relationships to treatments such as pulmonary rehabilitation are poorly understood [33]. However, it is in the brain that sensory inputs are integrated with anticipatory processes, anxious expectations, and learned associations in order to finally form the subjective experience of dyspnoea and the potential motivation for avoidance behaviour.

A laudable exception is the study by HerigSTAD et al. [34] in the present issue of this journal. The authors used functional magnetic resonance imaging (fMRI) to study brain activations in patients with COPD, which overcomes the limited spatial resolution of earlier studies in this patient group using near-infrared spectroscopy [35]. Specifically, before and after completing a standard 6-week outpatient pulmonary rehabilitation programme, brain responses were measured while patients were reading dyspnoea-related word cues (e.g. "climbing stairs", "walking uphill”) and rating how 1) breathless (i.e. breathlessness) and 2) anxious (i.e. breathlessness anxiety) these situations/contexts would make them feel. Changes over the course of pulmonary rehabilitation in these learned associations between cues of breathlessness and subjective breathlessness or breathlessness anxiety, respectively, were correlated with parallel changes in respective brain activations. Furthermore, these were related to pre/post changes in rehabilitation outcomes. Although this study is somewhat limited by the lack of a no treatment control group, it offers several notable findings.

First, the observed differences in the learned associations between word cues and breathlessness versus breathlessness anxiety in COPD patients lend further support for the important notion that sensory (i.e. intensity) and affective aspects of dyspnoea (i.e. unpleasantness, anxiety) are distinguishable dimensions of this symptom $[2-4,30]$. The overall experience of dyspnoea is based on an integration of these sensory and affective dimensions. If the latter dimension is amplified, this can increase the overall dyspnoea experience in the absence of sensory changes. Therefore, these different dimensions of dyspnoea should be assessed routinely with available and validated instruments [36].

Moreover, changes in these dimensions differed over the course of pulmonary rehabilitation. Significant group mean improvements were only observed in the ratings of breathlessness anxiety, and only these were further correlated with improvements in clinical dyspnoea ratings as measured with the D-12 [36]. This observation by HeRIGSTAD et al. [34] extends earlier findings demonstrating larger treatment responses for the affective compared to the sensory dimension of dyspnoea in COPD patients to learned dyspnoea-related associations [30, 37, 38].

Most importantly, the authors demonstrated in patients with COPD that changes in word cue-related breathlessness and breathlessness anxiety over the course of pulmonary rehabilitation were associated with parallel changes in the responses of distinct brain networks. These encompassed areas related to the processing of emotion, anxiety and nociception (stimulus valuation network) as well as attention regulation and motor networks. Notably, higher baseline activity in some of these areas was correlated with greater changes in word cue-related breathlessness and breathlessness anxiety over the course of 
pulmonary rehabilitation. These findings extend previous neuroimaging studies in healthy individuals that have demonstrated activations in a number of similar brain areas (e.g., insula, anterior cingulate cortex) during the perception $[39,40]$, but also during the anticipation of upcoming dyspnoea [24-28], which were partly related to subjective anxiety levels. In addition, the present neuroimaging findings support previous clinical observations that higher levels of dyspnoea-related fear were associated with greater impairment at the start of pulmonary rehabilitation, but with greater improvements after pulmonary rehabilitation including exercise-related dyspnoea [32].

Taken together, evidence is accumulating for the notion that the anxious expectation and anticipation of dyspnoea, dyspnoea-related fear and respective learned associations with situational/contextual cues might play a key role in COPD and contribute to worse outcomes [21]. They might enhance the affective dimension of dyspnoea (i.e. dyspnoea unpleasantness, dyspnoea anxiety) and, as a result, increase the overall experience of dyspnoea. Identifying and treating such maladaptive psychological constellations, for example with cognitive-behavioural treatment approaches embedded in pulmonary rehabilitation contexts, seems promising [41] and bears the potential to contribute to improvements in dyspnoea and a more favourable course of disease. Of course, intensified future interdisciplinary research efforts are required to establish which treatment strategy in which COPD patient is the most adequate for reducing his or her anxious expectations and, thus, for alleviating the burden of dyspnoea. In this regard, neuroimaging techniques as used by HERIGSTAD et al. [34] can certainly help in gaining a better understanding of the brain mechanisms underlying the interrelationships between dyspnoea and anxious expectations in COPD, help developing respective screening tools suited for routine clinical practice, and might even serve as a tool to guide the individualised selection as well as evaluation of respective treatments $[2,33]$.

\section{References}

1 Global Initiative for Chronic Obstructive Lung Disease (GOLD) Global Strategy for Diagnosis, Management, and Prevention of COPD. GOLD, 2016.

2 Parshall MB, Schwartzstein RM, Adams L, et al. An official American Thoracic Society statement: update on the mechanisms, assessment, and management of dyspnea. Am J Respir Crit Care Med 2012; 185: 435-452.

3 Laviolette L, Laveneziana P. Dyspnoea: a multidimensional and multidisciplinary approach. Eur Respir J 2014; 43: $1750-1762$.

4 Lansing RW, Gracely RH, Banzett RB. The multiple dimensions of dyspnea: review and hypotheses. Respir Physiol Neurobiol 2009; 167: 53-60.

5 Johnson MJ, Yorke J, Hansen-Flaschen J, et al. Towards an expert consensus to delineate a clinical syndrome of chronic breathlessness. Eur Respir J 2017; 49: 1602277.

6 Spruit MA, Singh SJ, Garvey C, et al. An official American Thoracic Society/European Respiratory Society statement: key concepts and advances in pulmonary rehabilitation. Am J Respir Crit Care Med 2013; 188: e13-e64.

7 Başoğlu M. Effective management of breathlessness: a review of potential human rights issues. Eur Respir J 2017; 49: 1602099.

8 Barnes PJ, Celli BR. Systemic manifestations and comorbidities of COPD. Eur Respir J 2009; 33: 1165-1185.

9 Vanfleteren LEGW, Spruit MA, Groenen M, et al. Clusters of comorbidities based on validated objective measurements and systemic inflammation in patients with chronic obstructive pulmonary disease. Am J Respir Crit Care Med 2013; 187: 728-735.

10 Maurer J, Rebbapragada V, Borson S, et al. Anxiety and depression in COPD: current understanding, unanswered questions, and research needs. Chest 2008; 134: 43S-56S

11 von Leupoldt A, Kenn K. The psychology of chronic obstructive pulmonary disease. Curr Opin Psychiatry 2013; 26: 458-463.

12 Yohannes AM, Alexopoulos GS. Depression and anxiety in patients with COPD. Eur Respir Rev 2014; 23: 345-349.

$13 \mathrm{Xu} \mathrm{W}$, Collet J-P, Shapiro S, et al. Independent effect of depression and anxiety on chronic obstructive pulmonary disease exacerbations and hospitalizations. Am J Respir Crit Care Med 2008; 178: 913-920.

14 von Leupoldt A, Taube K, Lehmann $\mathrm{K}$, et al. The impact of anxiety and depression on outcomes of pulmonary rehabilitation in patients with COPD. Chest 2011; 140: 730-736.

15 Livermore N, Butler JE, Sharpe L, et al. Panic attacks and perception of inspiratory resistive loads in chronic obstructive pulmonary disease. Am J Respir Crit Care Med 2008; 178: 7-12.

16 von Leupoldt A, Fritzsche A, Trueba AF, et al. Behavioral medicine approaches to chronic obstructive pulmonary disease. Ann Behav Med Publ Soc Behav Med 2012; 44: 52-65.

17 Smoller JW, Pollack MH, Otto MW, et al. Panic anxiety, dyspnea, and respiratory disease. Theoretical and clinical considerations. Am J Respir Crit Care Med 1996; 154: 6-17.

18 Troosters $\mathrm{T}$, van der Molen T, Polkey M, et al. Improving physical activity in COPD: towards a new paradigm. Respir Res 2013; 14: 115.

19 Leeuw M, Goossens MEJB, Linton SJ, et al. The fear-avoidance model of musculoskeletal pain: current state of scientific evidence. J Behav Med 2007; 30: 77-94.

20 Hayen A, Herigstad M, Pattinson KTS. Understanding dyspnea as a complex individual experience. Maturitas 2013; 76: 45-50.

21 von Leupoldt A, Janssens T. Could targeting disease specific fear and anxiety improve COPD outcomes? Expert Rev Respir Med 2016; 10: 835-837.

22 Esser RW, Stoeckel MC, Kirsten A, et al. Structural brain changes in patients with COPD. Chest 2016; 149: $426-434$. 
23 von Leupoldt A, Chan P-YS, Esser RW, et al. Emotions and neural processing of respiratory sensations investigated with respiratory-related evoked potentials. Psychosom Med 2013; 75: 244-252.

24 Faull OK, Jenkinson M, Ezra M, et al. Conditioned respiratory threat in the subdivisions of the human periaqueductal gray. eLife 2016; 27: e12047.

25 Holtz K, Pané-Farré CA, Wendt J, et al. Brain activation during anticipation of interoceptive threat. NeuroImage 2012; 61: 857-865.

26 Paulus MP, Flagan T, Simmons AN, et al. Subjecting elite athletes to inspiratory breathing load reveals behavioral and neural signatures of optimal performers in extreme environments. PloS One 2012; 7: e29394.

27 Stoeckel MC, Esser RW, Gamer M, et al. Amygdala response to anticipation of dyspnea is modulated by 5-HTTLPR genotype. Psychophysiology 2015; 52: 973-976.

28 Stoeckel MC, Esser RW, Gamer M, et al. Brain responses during the anticipation of dyspnea. Neural Plast 2016; 2016: 6434987

29 Vogelmeier CF, Criner GJ, Martinez FJ, et al. Global Strategy for the Diagnosis, Management, and Prevention of Chronic Obstructive Lung Disease 2017 Report: GOLD Executive Summary. Eur Respir J 2017; 49 : 1700214.

30 Carrieri-Kohlman V, Gormley JM, Eiser S, et al. Dyspnea and the affective response during exercise training in obstructive pulmonary disease. Nurs Res 2001; 50: 136-146.

31 Carrieri-Kohlman V, Douglas MK, Gormley JM, et al. Desensitization and guided mastery: treatment approaches for the management of dyspnea. Heart Lung J Crit Care 1993; 22: 226-234.

32 Janssens T, De Peuter S, Stans L, et al. Dyspnea perception in COPD: association between anxiety, dyspnea-related fear, and dyspnea in a pulmonary rehabilitation program. Chest 2011 ; 140: 618-625.

33 Binks A. Measuring the breathless brain: is real life too noisy? Eur Respir J 2015; 46: 1554-1556.

34 Herigstad M, Faull OK, Hayen A, et al. Treating breathlessness via the brain: changes in brain activity over a course of pulmonary rehabilitation. Eur Respir J 2017; 50: 1701029.

35 Higashimoto Y, Honda N, Yamagata T, et al. Exertional dyspnoea and cortical oxygenation in patients with COPD. Eur Respir J 2015; 46: 1615-1624.

36 Banzett RB, Moosavi SH. Measuring dyspnoea: new multidimensional instruments to match our 21st century understanding. Eur Respir J 2017; 49: 1602473.

37 Donesky D, Nguyen HQ, Paul SM, et al. The affective dimension of dyspnea improves in a dyspnea self-management program with exercise training. J Pain Symptom Manage 2014; 47: 757-771.

38 Wadell K, Webb KA, Preston ME, et al. Impact of pulmonary rehabilitation on the major dimensions of dyspnea in COPD. COPD 2013; 10: 425-435.

39 Evans KC. Cortico-limbic circuitry and the airways: insights from functional neuroimaging of respiratory afferents and efferents. Biol Psychol 2010; 84: 13-25.

40 Davenport PW, Vovk A. Cortical and subcortical central neural pathways in respiratory sensations. Respir Physiol Neurobiol 2009; 167: 72-86.

41 Livermore N, Dimitri A, Sharpe L, et al. Cognitive behaviour therapy reduces dyspnoea ratings in patients with chronic obstructive pulmonary disease (COPD). Respir Physiol Neurobiol 2015; 216: 35-42. 